\title{
Answer in Search of a Question
}

\section{Chandler Davis}

T

he cover of this issue of The Mathematical Intelligencer displays the full solution set of a combinatorialgeometric problem, to be explained below. The solution, and the problem, are due to Anthony Hill. Together they supply an answer to a problem in poetry.

The poet in the story was Hill's friend the late R.C. Kenedy, whose day job- poets tend to need day jobs-was as a librarian at the National Art Library in the Victoria \& Albert Museum. Kenedy had completed a poem, "The Legend of the Changeless Girl", consisting of 66 six-line stanzas, and the inspiration struck him that each stanza should be accompanied by a different geometric design. All of the same sort, of course. Hill being a devotee of this kind of combinatorics, he accepted the challenge of supplying 66 designs of the same sort but not isomorphic; and as mathematicians often will, he set himself the complementary demand that the list of designs be not only without duplications but also exhaustive. Why settle for "if" when you can have "if and only if", after all!
Failing to find a problem in his domain of mathematics whose complete list of solutions comprised exactly 66 objects, he set about trying to pose one. In an ambitious effort at still greater elegance, he demanded that the objects be graphs made up of exactly six lines each, in accord with the poem's six-line stanzas.

Some readers will want to glance back at our cover and identify what those doodles are. Maybe even to verify that they are non-isomorphic and are all the instances of what they are.

They are all the embeddings in the plane triangular lattice of the smallest planar graph with no symmetries. This graph had been found by G. Pólya some years before, and Hill knew a way to find all its embeddings. (See his article "The Continuous Charms of Discrete MathematicsSome Grassroot Problems in Ars Combinatoria" in Problemes combinatoires et théorie des graphes, CNRS, 1976, in particular p. 231.)

The poem by Kenedy for which this problem came into existence was never published, and is lost. Some young mathematician poet will perhaps be inspired by Hill's example to compose a poem of 66 six-line stanzas worthy of adornment by these emblems.

Department of Mathematics

New College, University of Toronto

Toronto, Ontario, M5S 3J6

Canada

e-mail: davis@math.toronto.edu 